\title{
Metodologia de Análise Qualitativa das Áreas Verdes Públicas: Um olhar sobre a Zona Norte da cidade de Cuiabá-MT
}

\section{Methodology for Qualitative Analysis of Public Green Areas: A look at the North Zone of the city of Cuiabá-MT}

Sandra Medina Benini ${ }^{1}$; Jeane Aparecida Rombi de Godoy ${ }^{2}$

\begin{abstract}
RESUMO
A presente pesquisa teve como objetivo a análise da qualidade das Áreas Verdes Públicas Urbanizadas (AVPUs), a exemplo de praças, jardins e parques urbanos, os quais são destinados ao lazer e recreação na cidade contemporânea. Como recorte espacial do estudo, optou-se pela Zona Norte da cidade de CuiabáMT. Para o desenvolvimento desta pesquisa qualitativa, foram adotados procedimentos metodológicos que tiveram como base lógica de investigação dividida em três fases: aberta ou exploratória, coleta de dados e análise e interpretação sistemática dos dados. Como resultado, verificou-se que a carência não só na quantidade de espaços públicos destinados ao lazer e recreação, bem como da qualidade desses espaços, o que denota a ausência de políticas públicas direcionadas para população de menor poder aquisitivo.
\end{abstract}

Palavras-chave: Cidade Contemporânea; Áreas Verdes Públicas Urbanizadas; Qualidade Ambiental;

\section{ABSTRACT}

This research aimed to analyze the quality of Urbanized Green Public Areas (AVPUs), such as squares, gardens and urban parks, which are intended for leisure and recreation in the contemporary city. As a spatial section of the study, the North Zone of the city of Cuiabá-MT was chosen. For the development of this qualitative research, methodological procedures were adopted that had the logical basis of investigation divided into three phases: open or exploratory, data collection and analysis and systematic interpretation of the data. As a result, it was found that the lack not only in the amount of public spaces for leisure and recreation, as well as the quality of these spaces, which denotes the absence of public policies aimed at the population with less purchasing power.

Keywords: Contemporary City; Urbanized Green Public Areas; Environmental Quality;

${ }^{1}$ Doutora em Geografia pela UNESP e em Arquitetura e Urbanismo pela UPM com PósDoutorado em Arquitetura e Urbanismo pela FAAC/UNESP; Pesquisadora da ANAP. E-mail: arquiteta.benini@gmail.com

2 Doutora em Arquitetura e Urbanismo pela UPM com Pós-Doutorado em Arquitetura e Urbanismo pela FAAC/UNESP, Docente da UNIVAG-MT. E-mail: urbanista.jeane@ gmail.com 


\section{INTRODUÇÃO}

O contexto das cidades, particularmente no Brasil, a carência de espaços públicos destinados ao lazer e recreação, assume o debate em diversas áreas do conhecimento. As Áreas Verdes Públicas Urbanizadas - AVPUs são bem conhecidas pelos benefícios ambientais, tais como: combate à poluição do ar; regulação a umidade e temperatura do ar; contribuição à permeabilidade, fertilidade e umidade do solo, protegendo contra processos erosivos; redução dos níveis de ruído servindo como amortecedor do barulho nas cidades, dentre outros. Em síntese, contribuem para conforto ambiental dos locais onde estão inseridas. Somam-se a estas funções a de embelezamento da cidade, bem como, a função do lazer, onde o homem pode afastar a angustia da cidade de concreto, permitindo que o indivíduo venha a se integrar com a natureza.

Diante da importância da temática proposta, optou-se pela realização desta análise qualitativa das AVPUs, tendo como recorte espacial a Zona Norte da cidade de Cuiabá-MT, a qual se justifica pelos aspectos ambientais do sítio, bem como, pela carência de espaços públicos destinado ao lazer e recreação a população.

\section{ESTADO DA ARTE}

Para apresentar o estado da arte sobre o tema, parte-se do pressuposto de que, as áreas verdes urbanas podem ser integradas a categoria de espaços livres na cidade, com características voltadas a recompor os elementos naturais, independente do porte de vegetação (MILANO, 1993). Nesse mesmo sentido, Cavalheiro et al. (1999) afirmam que área verde é "um tipo especial de espaços livres onde o elemento fundamental de composição é a vegetação". Sob este enfoque, Lima et al. (1994, p. 549) tece uma complementação, em que área verde é uma categoria de espaço livre, desde que haja predominância de vegetação arbórea, a exemplo das "praças, jardins públicos e parques urbanos".

Por sua vez, Nucci (2008, p.120) ao discutir a questão aborda a importância das funções desempenhadas pelos espaços vegetados, ao considerar que, para uma área ser identificada como área verde deve haver a "predominância de áreas plantadas e que deve cumprir três funções (estética, ecológica e lazer)", além de apresentar uma cobertura vegetal e "solo permeável (sem laje) que devem ocupar, pelo menos, $70 \%$ da área".

Independentemente de seu enquadramento quanto a titulação, sejam as áreas verdes de propriedade pública ou privada, em qualquer das duas categorias devem 
apresentar algum tipo de vegetação (não somente árvores) com dimensão vertical significativa, torna-se relevante que as mesmas sejam utilizadas com objetivos sociais, ecológicos, científicos ou culturais (NOGUEIRA; WANTUELFER, 2002).

Para tanto, no âmbito desta pesquisa, considera-se área verde pública o conteúdo expresso no conceito, para o qual:

[...] todo espaço livre (área verde / lazer) que foi afetado como de uso comum e que apresente algum tipo de vegetação (espontânea ou plantada), que possa contribuir em termos ambientais (fotossíntese, evapotranspiração, sombreamento, permeabilidade, conservação da biodiversidade e mitigue os efeitos da poluição sonora e atmosférica) e que também seja utilizado com objetivos sociais, ecológicos, científicos ou culturais. (BENINI, 2009, p. 71).

Como esses espaços são de uso comum do povo, impõem à Administração Municipal, bem como à "coletividade (a sociedade como um todo) o dever de defender e preservar tais espaços (áreas verdes públicas), visto que os mesmos podem contribuir para a sadia qualidade de vida e, consequentemente, para a qualidade ambiental" (BENINI, 2009).

Os estudos elaborados por Nucci (2008, p. 109) dão ênfase as condições de conforto propiciadas pelas áreas verdes, onde é comum encontrar um ambiente agradável, afastando a "angústia" da cidade, possibilitando ao indivíduo uma interação com a natureza.

Esses ambientes devem ser agradáveis e estéticos, com acomodações e instalações variadas de modo a facilitar a escolha individual. Devem ser livres de monotonia e isentos das dificuldades de espaço e da angústia das aglomerações urbanas. Principalmente para as crianças é fundamental que o espaço livre forneça a possibilidade de experimentar sons, odores, texturas, paladar da natureza; andar descalço pela areia, gramado; ter contato com animais como pássaros, pequenos mamíferos e insetos, etc. (NUCCI, 2008, p. 109)

Gomes (2005, p. 57) complementa a afirmação de Nucci (2008, p. 109), apontando que as áreas verdes, "do ponto de vista psicológico e social, influenciam o estado de ânimo dos indivíduos massificados com o transtorno das grandes cidades". O autor também afirma que a vegetação oferece benefícios ambientais como, por exemplo: 
combate à poluição do $\mathrm{ar}^{3}$ através da fotossíntese ${ }^{4}$; "regula a umidade e temperatura do ar; mantém a permeabilidade, fertilidade e umidade do solo e protege-o contra a erosão e; reduz os níveis de ruído servindo como amortecedor do barulho das cidades".

Troppmair e Galina (2003) acrescentam, enfatizando as vantagens das áreas verdes:

a) Criação de microclima mais ameno que exerce função de centro de alta pressão e se reflete de forma marcante sobre a dinâmica da ilha de calor [...];

b) Despoluição do ar de partículas sólidas e gasosas, dependendo do aparelho foliar, rugosidade da casca, porte e idade das espécies arbóreas;

c) Redução da poluição sonora, especialmente por espécies aciculiformes (pinheiros) que podem acusar redução de 6 a 8 decibéis; d) Purificação do ar pela redução de microorganismos. Foram medidos 50 microorganismos por metro cúbico de ar de mata e até 4.000 .000 por metro cúbico em shopping centers;

e) Redução da intensidade do vento canalizado em avenidas cercadas por prédios;

f) Vegetação como moldura e composição da paisagem junto a monumentos e edificações históricas.

Neste contexto analítico, Loboda e Angelis (2005) afirmam que as áreas verdes urbanas contribuem para a melhoria da qualidade de vida nas cidades. Segundo Gomes (2005, p. 115) as áreas verdes podem proporcionar conforto térmico ${ }^{5}$, visto que essas superfícies verdes interferem na formação de microclimas ${ }^{6}$.

\footnotetext{
3 “Gases venenosos em suspensão no ar acima da rua e a poeira tóxica cobrem a via carroçável e as calçadas. Automóveis, ônibus e caminhões congestionam as ruas, acelerando e freando, emitindo torrentes de monóxidos de carbono, óxidos de nitrogênio e partículas de chumbo e de combustível não queimado. $\mathrm{O}$ pára-e-anda do tráfego, característico de uma rua movimentada, produz mais poluentes do que um tráfego que flui suavemente a uma velocidade constante ao longo de uma rodovia, porque a concentração de fumaça dos escapamentos é maior, numa taxa irregular de combustão. Gotículas de óleo dos motores se transformam num fino aerossol; asbestos desprendem-se dos freios; a pavimentação das ruas literalmente tritura a borracha dos pneus em uma poeira fina" (SPIRN, 1995, p. 71).

4 "A fotossíntese auxilia na umidificação do ar, consequente resfriamento evaporativo" (BARBIRATO; SOUZA; TORRES, 2007, p.113-114).

5 “Conforto térmico - Engloba as componentes termodinâmicas que, em suas relações, se expressam através do calor, ventilação e umidade nos referenciais básicos a esta noção. É um filtro perceptivo bastante significativo, pois afeta a todos permanentemente. Constitui, seja na climatologia médica, seja na tecnologia habitacional, assunto de investigação de importância crescente" (MONTEIRO, 2003, P. 2 4). "A sensação de conforto térmico está associada com o ritmo de troca de calor entre o corpo e o meio ambiente, sendo assim, o desempenho humano durante qualquer atividade pode ser otimizado, desde que o ambiente propicie condições de conforto e que sejam evitadas sensações desagradáveis, tais como: dificuldade de eliminar o excesso de calor produzido pelo organismo; perda exagerada de calor pelo corpo e desigualdade de temperatura entre as diversas partes do corpo" (BARBIRATO; SOUZA; TORRES, 2007, p.144).

6 "Cada cidade é composta por um mosaico de microclimas radicalmente diferentes, os quais são criados pelos mesmos processos que operam na escala geral da cidade. Os mesmos fenômenos que caracterizam o mesoclima urbano existem em miniatura por toda a cidade - pequenas ilhas de calor, microinversões,
} 
Spirn (1995, p. 68-69) explica que as áreas verdes diferem da paisagem de concreto, pela sua capacidade de dispersar a radiação solar, através da evaporação e transpiração.

\begin{abstract}
$\mathrm{Na}$ cidade, concreto, pedra, tijolo e asfalto substituem a cobertura vegetal natural do campo. Esses materiais absorvem o calor mais rapidamente e o mantém em maiores quantidades do que as plantas, o solo e a água. [...] Durante o dia todo, o calçamento, as paredes e os telhados absorvem e conservam o calor da irradiação solar. Embora a água e as plantas absorvam também a radiação solar, a maior parte dessa energia é gasta na evaporação e transpiração - resultando numa perda de calor maior do que é absorvido. [...] A cidade esfria mais lentamente: ela absorveu mais calor, e a irradiação desse calor para o céu noturno é inibida pelas paredes dos edifícios. (SPIRN, 1995, p. 68-9).
\end{abstract}

Do mesmo modo, Danni-Oliveira (2003, p. 157) com base nos estudos de climatologia urbana, afirma que as áreas residenciais, quando "ladeadas por áreas verdes", recebem "incidência da radiação solar", através das "trocas dos fluxos de calor e de umidade, bem como a dispersão de poluentes".

Num contexto mais amplo, as relevâncias das áreas verdes pública presentes no tecido urbano, reitera a necessidade de incorporar os princípios de preservação e conservação, de onde emerge o conceito de sustentabilidade urbana, o qual pode interferir favoravelmente não apenas na melhoria da qualidade ambiental, mas principalmente na qualidade de vida urbana.

A oferta de espaços públicos é um dos requisitos para a efetivação ao direito a cidade, uma vez que esses locais agregam "valores visuais ou paisagísticos, valores recreativos e valores ambientais" no ambiente urbano e que "uma boa qualidade do espaço público pode fornecer a permanência em uma espacialidade tranqüila, o desenvolvimento de atividades sociais e, consequentemente, vitalidade urbana" (BARBIRATO; SOUZA; TORRES, 2007, p.144).

Neste contexto, as áreas verdes públicas, ou seja, jardins ${ }^{7}$ e parques $\operatorname{urbanos}^{8}$ vêm "exercer um importante papel na identidade dos lugares, muitas vezes ressaltando as

bolsões de grave poluição atmosférica e diferenças locais no comportamento dos ventos" (SPIRN, 1995, p. 71).

${ }^{7}$ Um jardim público compreende aqueles cuja manutenção fica ao encargo dos poderes públicos e se destinam ao uso e gozo da população em geral, com as limitações necessárias a sua função [...] (NIEMEYER, 2005, p.10).

8 “Considera como parque todo espaço de uso público destinado à recreação de massa, qualquer que seja o seu tipo, capaz de incorporar intenções de conservação e cuja estrutura morfológica é auto-suficiente, isto 
características físicas do sítio" urbano (PISSOL, 2006, p. 2). A implantação de um jardim ou parque urbano contribui para a humanização da cidade.

Os parques e jardins - As mais belas realizações da humanidade são produtos do ideal. Basta recordar os maravilhosos parques, jardins e monumentos sobreviventes de todas as grandes civilizações, para se compreender a força criadora de uma visão de longo alcance, capaz de dar forma e beleza aos elementos mais diversos, a fim de legá-los à posteridade. (LOUREIRO, 1979, p. 24)

A criação, produção e reprodução desses espaços no tempo agregam valores urbanísticos, essenciais ao arranjo espacial do sítio urbano. Loureiro (1979, p. 33) afirma que a cidade deve ser pensada e produzida, considerando as áreas verdes púbicas como requisito básico à qualidade urbana. Para Robba e Macedo (2003, p. 44-45), essa qualidade urbana, está implícita nos valores ambientais, funcionais, estéticos e simbólicos dessas áreas.

\section{METODOLOGIA}

Para a delimitação do universo a ser estudado, optou-se por uma pesquisa qualitativa, em que os procedimentos tiveram uma base lógica que consistiu na investigação dividida em três fases: "aberta ou exploratória", "coleta de dados" e "análise e interpretação sistemática dos dados" (LÜDKE; ANDRÉ, 1986, p. 21).

A primeira fase da pesquisa, conhecida como aberta ou exploratória, consistiu do exame da literatura pertinente a livros, teses, dissertações, artigos, etc. sobre a temática, com repetição constante dos mesmos referenciais bibliográficos, sem apresentação de novas proposituras que viessem a ampliar a discussão teórica.

A segunda fase da pesquisa consistiu na coleta dos dados in loco (realizada 2019 e tabulação em 2020), tendo como subsídio os trabalhos de Angelis, Castro e Angelis Neto (2004), Santiago, Santiago e Soares (2016) e na NBR 9050/2015, para a definição dos procedimentos metodológicos necessários. Nesta fase foram utilizados a base cartográfica da Prefeitura Muncipal de Cuiabá e os dados do IBGE (2010).

é, não é diretamente influenciada em sua configuração por nenhuma estrutura construída em seu entorno" (MACEDO; SAKATA, 2002, p. 14). 
A terceira fase consistiu da inserção do objeto de pesquisa dentro de um quadro de referenciais teóricos, concomitantemente com a construção empírica, o que permitiu a obtenção dos produtos desta pesquisa.

\section{PROCEDIMENTOS PARA AVALIAÇÃO DAS AVPUS}

Uma vez verificada a implantação das AVPUs no bairro, consideraram-se os seguintes requisitos para análise: acessibilidade, vegetação, quantidade e qualidade dos mobiliários implantados e a oferta dos serviços públicos. Para a construção da pesquisa empírica, foram considerados atributos e variáveis pré-estabelecidas, conforme apresentado a seguir:

a) para aferir a qualidade da acessibilidade nas AVPUs, foram considerados o estado de conservação do piso, a existência e o dimensionamento das rotas de circulação, barreiras naturais que pudessem comprometer a acessibilidade, a oferta de rampa e piso tátil de alerta e direcionamento, bem como a oferta de estacionamento, inclusive para idosos (Quadro 1):

Quadro 1 - Atribuição de peso (valor) à acessibilidade na AVPU

\begin{tabular}{|c|c|c|c|}
\hline ATRIBUTO & VARIÁVEIS & SITUAÇÃO & PESO \\
\hline \multirow{19}{*}{ Acessibilidade } & \multirow{3}{*}{$\begin{array}{l}\text { Estado de conservação do piso no espaço } \\
\text { (AVPU) }\end{array}$} & bom & 2 \\
\hline & & razoável & 1 \\
\hline & & ruim & 0 \\
\hline & \multirow{2}{*}{$\begin{array}{l}\text { As rotas de circulação são inferiores a } 1,20 \\
\text { metro }\end{array}$} & $\operatorname{sim}$ & 0 \\
\hline & & não & 2 \\
\hline & \multirow{2}{*}{$\begin{array}{l}\text { Existência de pelo menos uma rota acessível } \\
\text { no interior do espaço (AVPU) }\end{array}$} & $\operatorname{sim}$ & 2 \\
\hline & & não & 0 \\
\hline & \multirow{2}{*}{$\begin{array}{l}\text { A vegetação do espaço (AVPU) interrompe } \\
\text { a rota acessível }\end{array}$} & $\operatorname{sim}$ & 0 \\
\hline & & não & 2 \\
\hline & \multirow{2}{*}{ Tem rampa de acesso } & $\operatorname{sim}$ & 2 \\
\hline & & não & 0 \\
\hline & \multirow{2}{*}{ Tem piso tátil de alerta e direcional } & $\operatorname{sim}$ & 2 \\
\hline & & não & 0 \\
\hline & \multirow{2}{*}{$\begin{array}{l}\text { No entorno do espaço (AVPU) há vagas } \\
\text { reservadas para pessoas com deficiência }\end{array}$} & $\operatorname{sim}$ & 2 \\
\hline & & não & 0 \\
\hline & \multirow{2}{*}{$\begin{array}{l}\text { No entorno da praça (AVPU) há vagas } \\
\text { reservadas para idosos }\end{array}$} & $\operatorname{sim}$ & 2 \\
\hline & & não & 0 \\
\hline & \multirow{2}{*}{ Estacionamento } & $\operatorname{sim}$ & 2 \\
\hline & & não & 0 \\
\hline
\end{tabular}

Fonte: BENINI, 2020. 
b) a qualidade do atributo "vegetação" foi mensurado, considerando critérios com a oferta de espaços arborizados e vegetação rasteira, o tratamento paisagístico, bem como o percentual de permeabilidade nas AVPUs (Quadro 2):

Quadro 2 - Atribuição de peso (valor) à vegetação na AVPU

\begin{tabular}{|l|l|c|c|}
\hline ATRIBUTO & VARIÁ VEIS & SITUAÇÃO & PESO \\
\hline \multirow{5}{*}{ Vegetação } & \multirow{2}{*}{ Espaço é arborizado } & sim & 3 \\
\cline { 2 - 4 } & \multirow{2}{*}{ Espaço tem vegetação rasteira } & não & 0 \\
\cline { 2 - 4 } & \multirow{2}{*}{ O espaço tem tratamento paisagístico } & não & 3 \\
\cline { 2 - 4 } & & sim & 3 \\
\cline { 2 - 4 } & \multirow{3}{*}{ Permeabilidade (\%) } & não & 0 \\
\cline { 2 - 4 } & & de 50 a 75\% & 2 \\
\cline { 2 - 3 } & & de 25 a 49\% & 1 \\
\cline { 2 - 3 } & & inferior a 25\% & 0 \\
\hline
\end{tabular}

Fonte: BENINI, 2020.

c) Para avaliar a qualidade dos mobiliários destinados à recreação, foram considerados a oferta de parque infantil, equipamentos de exercício (academia ao ar livre), equipamentos de ginástica para terceira idade, bem como se nas AVPUs havia a instalação de quadra esportiva (Quadro 3).

Quadro 3 - Atribuição de peso (valor) aos mobiliários destinados à recreação na AVPU

\begin{tabular}{|c|c|c|c|}
\hline ATRIBUTO & VARIÁVEIS & SITUAÇÃO & PESO \\
\hline \multirow{8}{*}{$\begin{array}{l}\text { Mobiliários } \\
\text { destinados à } \\
\text { recreação }\end{array}$} & \multirow{2}{*}{ Parque infantil } & $\operatorname{sim}$ & 3 \\
\hline & & não & 0 \\
\hline & \multirow{2}{*}{$\begin{array}{l}\text { Equipamentos de exercícios - Academia ao } \\
\text { ar livre }\end{array}$} & $\operatorname{sim}$ & 3 \\
\hline & & não & 0 \\
\hline & \multirow{2}{*}{$\begin{array}{l}\text { Equipamentos de ginástica para terceira } \\
\text { idade }\end{array}$} & sim & 3 \\
\hline & & não & 0 \\
\hline & \multirow{2}{*}{ Quadra esportiva } & $\operatorname{sim}$ & 3 \\
\hline & & não & 0 \\
\hline
\end{tabular}

Fonte: BENINI, 2020.

d) dentre os atributos avaliados, na questão cultural foram considerados a instalação de palco para apresentação artísticas, chafariz e espelho d'água e 
exposição de obras de arte, a exemplo de esculturas, bustos, entre outros (Quadro 4):

Quadro 4 - Atribuição de peso (valor) aos mobiliários destinados à cultura na AVPU

\begin{tabular}{|c|c|c|c|}
\hline ATRIBUTO & VARIÁVEIS & SITUAÇÃO & PESO \\
\hline \multirow{6}{*}{ Cultura } & \multirow{2}{*}{ Palco } & $\operatorname{sim}$ & 2 \\
\hline & & não & 0 \\
\hline & \multirow[t]{2}{*}{ Obra de arte } & $\operatorname{sim}$ & 2 \\
\hline & & não & 0 \\
\hline & \multirow{2}{*}{ Chafariz / espelho d'água } & $\operatorname{sim}$ & 2 \\
\hline & & não & 0 \\
\hline
\end{tabular}

Fonte: BENINI, 2020.

e) a qualidade do mobiliário em geral, considerou o valor/peso atribuído para cada variável do Quadro 5, de modo a permitir uma análise sistemática das AVPUs:

Quadro 5 - Atribuição de peso (valor) aos mobiliários em geral na AVPU

\begin{tabular}{|c|c|c|c|}
\hline ATRIBUTO & VARIÁVEIS & SITUAÇÃO & PESO \\
\hline \multirow{22}{*}{$\begin{array}{l}\text { Mobiliário em } \\
\text { geral }\end{array}$} & \multirow{2}{*}{ Bancos } & $\operatorname{sim}$ & 3 \\
\hline & & não & 0 \\
\hline & \multirow{2}{*}{ Bebedor } & $\operatorname{sim}$ & 3 \\
\hline & & não & 0 \\
\hline & \multirow{2}{*}{ Iluminação alta } & $\operatorname{sim}$ & 3 \\
\hline & & não & 0 \\
\hline & \multirow{2}{*}{ Iluminação baixa } & $\operatorname{sim}$ & 3 \\
\hline & & não & 0 \\
\hline & \multirow{2}{*}{ Lixeira } & sim & 3 \\
\hline & & não & 0 \\
\hline & \multirow{2}{*}{ Sanitário } & sim & 2 \\
\hline & & não & 0 \\
\hline & \multirow{2}{*}{ Ponto de ônibus } & $\operatorname{sim}$ & 1 \\
\hline & & não & 0 \\
\hline & \multirow{2}{*}{ Ponto de táxi } & $\operatorname{sim}$ & 1 \\
\hline & & não & 0 \\
\hline & \multirow{2}{*}{ Banca de revista } & $\operatorname{sim}$ & 1 \\
\hline & & não & 0 \\
\hline & \multirow{2}{*}{ Telefone público } & $\operatorname{sim}$ & 1 \\
\hline & & não & 0 \\
\hline & \multirow{2}{*}{ Quiosque } & $\operatorname{sim}$ & 1 \\
\hline & & não & 0 \\
\hline
\end{tabular}

Fonte: BENINI, 2020. 
f) Ademais, a pesquisa contemplou a avaliação dos serviços públicos ofertados nas AVPUs, tais como conservação e limpeza do espaço. Nesta etapa, também foi considerada a oferta de segurança (vigia) no local (Quadro 6):

Quadro 6 - Atribuição de peso (valor) a oferta de serviço público na AVPU

\begin{tabular}{|l|l|c|c|}
\hline ATRIBUTO & VARIÁVEIS & SITUAÇÃO & PESO \\
\hline \multirow{4}{*}{$\begin{array}{l}\text { Serviço } \\
\text { público }\end{array}$} & \multirow{2}{*}{ Conservação do espaço } & bom & 2 \\
\cline { 2 - 4 } & & razoável & 1 \\
\cline { 2 - 4 } & \multirow{2}{*}{ Limpeza no espaço } & ruim & 0 \\
\cline { 3 - 4 } & & bom & 2 \\
\cline { 2 - 4 } & \multirow{2}{*}{ Tem segurança (vigia) no local } & razoável & 1 \\
\cline { 2 - 4 } & & suim & 0 \\
\cline { 2 - 4 } & & não & 0 \\
\hline
\end{tabular}

Fonte: BENINI, 2020.

A conjugação desses atributos apresentados, considerando suas variáveis, permitiu que fossem gerados alguns produtos de análises, como tabelas e mapas, os quais permitiram especializar a qualidade das AVPUs.

A partir desses dados foi aferido o Índice de Área Verde Pública Urbanizada (IAVPU) por bairro da zona oeste da cidade de Cuiabá, por intermédio da interpolação de dados na seguinte fórmula:

IAVPU = Índice de Área Verde Pública Urbanizada por bairro

$\sum\{$ AVP Urbanizada $:$ hab $\}=\operatorname{IAVPU}\left(\mathrm{m}^{2} / \mathrm{hab}\right)$

Assim, considerando a metodologia apresentada, destaca-se ainda que a mesma pode ser replicada não só nas demais zonas da cidade de Cuiabá, mas em qualquer cidade do território brasileiro.

\section{ESTUDO DE CASO}

Para o desenvolvimento deste trabalho, optou-se como recorte espacial a Zona Norte da cidade Cuiabá, Estado do Mato Grosso, que possui área de 3.538,17 Km2, correspondendo a 254,57 Km2 à área urbana e 3.283,60 Km2 à área rural. Faz divisa com 
os municípios de Acorizal, Rosário Oeste, Chapada dos Guimarães, Santo Antônio do Leverger e Várzea Grande (Figura 1).

Figura 1 - Localização de Cuiaba-MT.

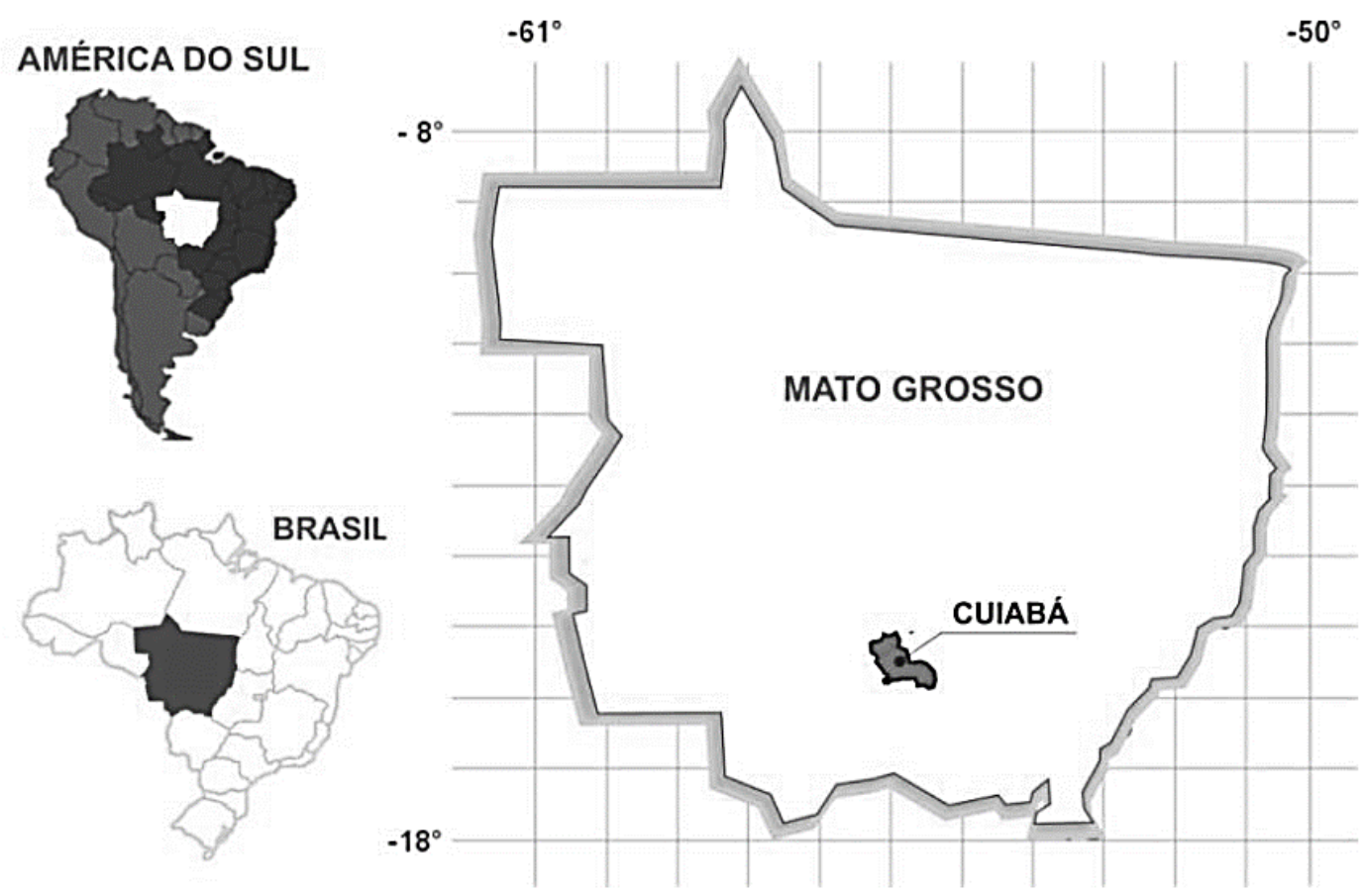

Fonte: ÁVILA, 2015, p. 4.

A cidade Cuiabá esta localizada na Baixada Cuiabana, onde segundo Ávila (2015, p. 4), na região há predominancia de um "clima Tropical Continental, sem influência marítima, onde já foi detectada a interferência do uso do solo urbano na ocorrência de ilhas de calor", a região "apresenta baixa frequência e velocidade média dos ventos, que torna a influência do espaço construído sobre a temperatura do ar mais perceptível, já que as trocas térmicas por convecção são minimizadas”, deste modo temse há predominância de temperaturas elevadas, com chuva no verão e inverno com clima seco .

Segundo dados do Censo IBGE (2010), 36, 41\% da população da Zona Norte da cidade de Cuiabá encontra-se na faixa de 0 a 19 anos (crianças e adolecentes), dados estes que denotam a necessidade de implantação de políticas públicas para atendimento deste público (Tabela 1). 
Tabela 1 - População (Crianças e Adolecentes) da Zona Norte da Cidade de Cuiabá-MT

\begin{tabular}{|c|c|c|c|c|c|c|}
\hline \multirow[b]{2}{*}{ Cd. } & \multirow[b]{2}{*}{ BAIRRO ZONA NORTE } & \multirow[b]{2}{*}{ POPULAÇÃ̃O ${ }^{(\mathbf{1})}$} & \multicolumn{4}{|c|}{ GRUPOS ETÁRIOS (\%) } \\
\hline & & & $\begin{array}{l}\text { 0 a } 4 \\
\text { anos }\end{array}$ & $\begin{array}{l}5 \text { a } 9 \\
\text { anos }\end{array}$ & $\begin{array}{l}10 \text { a } 14 \\
\text { anos }\end{array}$ & $\begin{array}{l}16 \text { a } 19 \\
\text { anos }\end{array}$ \\
\hline 25 & Jardim Florianópolis & 4.824 & 9,12 & 8,46 & 10,84 & 11,40 \\
\hline 26 & Jardim Vitória & 8.966 & 9,21 & 8,20 & 10,86 & 11,97 \\
\hline 27 & Paraíso & 5.655 & 9,07 & 10,45 & 10,75 & 10,80 \\
\hline 28 & Nova Conquista & 855 & 8,77 & 7,37 & 10,18 & 10,53 \\
\hline 29 & Primeiro de Março & 7.457 & 8,65 & 9,59 & 10,57 & 11,30 \\
\hline 30 & Três Barras & 9.926 & 9,96 & 9,30 & 10,36 & 10,71 \\
\hline 31 & Morada da Serra & 56.066 & 6,50 & 6,38 & 7,43 & 8,62 \\
\hline 32 & Morada do Ouro & 5.824 & 5,25 & 6,06 & 6,71 & 8,46 \\
\hline 33 & Centro Político Administrativo & 5.434 & 9,83 & 9,49 & 9,60 & 10,09 \\
\hline 34 & Paiaguás & 4.743 & 7,72 & 7,97 & 8,24 & 8,67 \\
\hline 117 & Área de Expansão Urbana & 11.164 & 9,57 & 9,16 & 9,04 & 7,32 \\
\hline
\end{tabular}

1 - População segundo dados coletados pelo Censo IBGE, 2010

Fonte: IBGE, 2010 - Organizado pelas Autoras

Ao observar os dados econômicos, verificou-se que o rendimento médio da população an região é baixo, comprometendo assim, a qualidade de vida de seus moradores. Fato este, que reforça a importância da oferta de espaços públicos para esses moradores, destinados ao lazer e recreação, considerando que muitos não tem acesso a clubes, shopping, academias, etc.

Tabela 2 - Rendimentos Médio da População na Zona Norte da Cidade de Cuiabá-MT

\begin{tabular}{l|l|c|c}
\hline Cd. & BAIRRO & POPULAÇÃO $^{(\mathbf{1})}$ & RENDIMENTO MÉDIO (SM) $^{(2)}$ \\
\hline 25 & Jardim Florianópolis & 4.824 & 2,25 \\
\hline 26 & Jardim Vitória & 8.966 & 2,24 \\
\hline 27 & Paraíso & 5.655 & 2,41 \\
\hline 28 & Nova Conquista & 855 & 2,41 \\
\hline 29 & Primeiro de Março & 7.457 & 2,59 \\
\hline 30 & Três Barras & 9.926 & 2,41 \\
\hline 31 & Morada da Serra & 56.066 & 5,18 \\
\hline 32 & Morada do Ouro & 5.824 & 11,69 \\
\hline 33 & Centro Político & 5.434 & 2,72 \\
& Administrativo & & 6,03 \\
\hline 34 & Paiaguás & 4.743 & - \\
\hline 117 & Área de Expansão Urbana & 11.164 & \\
\hline
\end{tabular}

1 - População segundo dados coletados pelo Censo IBGE, 2010

2 - Rendimentos Médios (SM) - como base para este trabalho utilizaram-se os dados da tabela "Valor do rendimento nominal médio mensal, valor do rendimento nominal mediano mensal das pessoas com rendimento, responsáveis pelos domicílios particulares permanentes, segundo os bairros" do Censo Demográfico2000 (resultados do universo), divulgado pelo IBGE.

Fonte: IBGE, 2010 - Organizado pelas Autoras 


\section{RESULTADOS}

Durante a realização desta pesquisa, verificou-se uma carência na oferta de AVPUs na Zona Norte da Ciade de Cuiabá, apresentando assim, um descompaço com a Lei de Parcelamento de Solo (Lei $n^{\circ}$ 6.766/1979), a qual determina em seu artigo 22, quais os equipamentos urbanos (vias e praças, os espaços livres e as áreas destinadas a edifícios públicos e outros equipamentos urbanos) que, após o registro do loteamento, passam a integrar os bens de domínio público.

Sabe-se que as Administrações Públicas têm restrições orçamentárias para atender todas as demandas urbanas (saúde, educação, serviços sociais, entre outros), e por esta razão, acaba sendo destinado um valor insuficiente do orçamento para implantação desses espaços.

Os resultados obtidos pela análise qualitativa das AVPUs, demonstraram que os bairros que obtiveram uma pontuação elevada, com exceção do Centro Político Admininstrativo, são bairros de classe média segundo o IBGE (2010), a exemplo da Morada do Ouro e Bairro Paiaguais.

Tabela 3 - Síntese da Avaliação Qualitativa das AVPU da Zona Norte da Cidade de Cuiabá-MT.

\begin{tabular}{|c|c|c|c|c|c|}
\hline Cd. & $\begin{array}{l}\text { BAIRRO DA } \\
\text { ZONA NORTE }\end{array}$ & $\begin{array}{l}\text { ÁREA VERDE } \\
\text { PÚBLICA } \\
\text { URBANIZADA }\end{array}$ & M2 & $\underset{\text { (1) }}{\text { QUALIDADE }}$ & $\begin{array}{l}\text { MÉDIA } \\
\text { Q. }{ }^{\text {(2) }}\end{array}$ \\
\hline 25 & \begin{tabular}{|l|} 
Jardim \\
Florianópolis \\
\end{tabular} & $\begin{array}{l}\text { Praça Arquiteto Júlio de } \\
\text { Lamonica Freire }\end{array}$ & $2.427,98$ & 27 & 27 \\
\hline \multirow[t]{3}{*}{30} & \multirow[t]{3}{*}{ Três Barras } & $\begin{array}{l}\text { Praça Residencial Nova } \\
\text { Canaã }\end{array}$ & $3.049,35$ & 39 & \multirow[t]{3}{*}{26,6} \\
\hline & & Praça Jardim Umurana & $1.980,32$ & 20 & \\
\hline & & Praça Três Barras & $2.074,98$ & 21 & \\
\hline \multirow{8}{*}{31} & \multirow{8}{*}{ Morada da Serra } & Espaço Sem Denominação & $15.540,95$ & 40 & \multirow{8}{*}{27,3} \\
\hline & & $\begin{array}{l}\text { Praça de Esporte E Lazer } \\
\text { Ermes do Nascimento } \\
\text { Justino }\end{array}$ & $4.995,49$ & 31 & \\
\hline & & Praça da Caixa D'água & $1.982,70$ & 31 & \\
\hline & & Espaço Sem Denominação & $2.1744,93$ & 33 & \\
\hline & & Praça do Cpa I & $2.340,16$ & 11 & \\
\hline & & Praça do Ginásio Verdinho & $9.337,54$ & 35 & \\
\hline & & Espaço sem Denominação & $3.124,49$ & 20 & \\
\hline & & $\begin{array}{l}\text { Parque Municipal Lagoa } \\
\text { Encantada }\end{array}$ & $3.519,00$ & 18 & \\
\hline
\end{tabular}




\begin{tabular}{c|l|l|c|c|c}
\hline \multirow{2}{*}{ Cd. } & $\begin{array}{l}\text { BAIRRO DA } \\
\text { ZONA NORTE }\end{array}$ & $\begin{array}{l}\text { ÁREA VERDE } \\
\text { PÚBLICA } \\
\text { URBANIZADA }\end{array}$ & M2 & $\begin{array}{c}\text { QUALIDADE } \\
\text { (1) }\end{array}$ & $\begin{array}{c}\text { MÉDIA } \\
\text { Q. }\end{array}$ \\
\hline \multirow{2}{*}{32} & Morada do Ouro & $\begin{array}{l}\text { Praça Cultural Morada do } \\
\text { Ouro }\end{array}$ & $3.641,00$ & 38 & 38 \\
\hline \multirow{2}{*}{33} & \multirow{2}{*}{$\begin{array}{l}\text { Centro Político } \\
\text { Administrativo }\end{array}$} & Praça Sem. Jonas Pinheiro & $11.336,00$ & 38 & \multirow{2}{*}{4} \\
\cline { 3 - 5 } & $\begin{array}{l}\text { Parque Massairo Okamura } \\
\text { Praça Monumento Ulisses } \\
\text { Guimarães }\end{array}$ & $540.000,00$ & 50 & \multirow{2}{*}{45} \\
\cline { 3 - 5 } & Parque das Águas & $270.000,00$ & 59 & \multirow{2}{*}{43} \\
\hline 34 & Bairro Paiaguais & Espaço sem Denominação & 4094,95 & 43 & \\
\hline
\end{tabular}

1 - Qualidade das AVPU - Área Verde Pública Urbanizada (praças, jardins e parques)

2 - Média da qualidade aferida por bairro

Fonte: Organizado pelas Autoras

A Figura 2 demonstra a contradição presente na implantação de políticas públicas destinado ao lazer e recreação na região, pois onde há população tem menor rendimento, a qualidade das AVPUs é baixa, ou simplesmente, não foram implantadas, a exemplo do Jardim Vitória, Paraiso e Nova Conquista, Primeiro de Março.

Figura 2 - Mapa da Avaliação Qualidade das AVPU da Zona Norte da Cidade de Cuiabá-MT

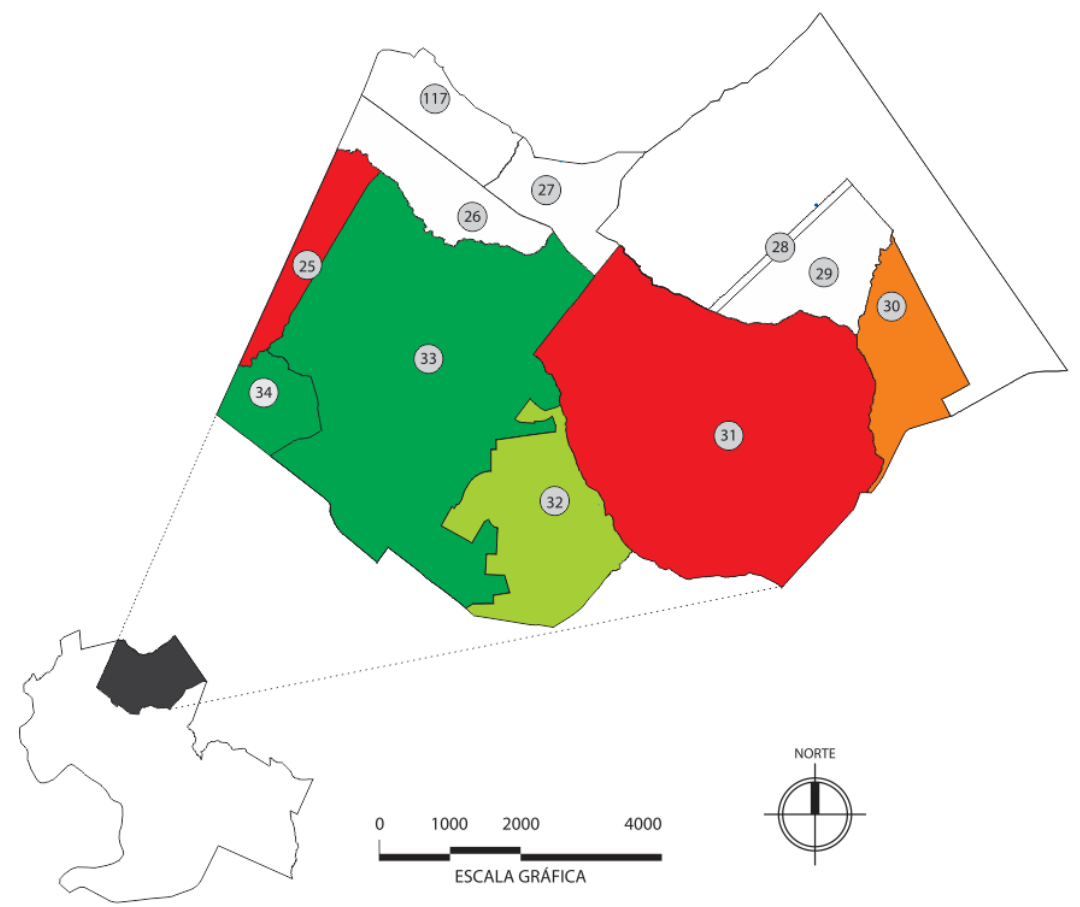

LEGENDA

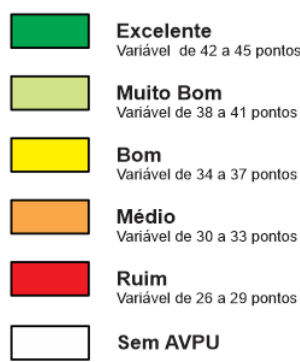

BAIRROS

25. Jardim Florianópolis

26. Jardim Vitória

27. Paraíso

28. Nova Conquista

29. Primeiro de Março

30. Três Barras

31. Morada da Serra

32. Morada do Ouro

33. Centro Político Administrativo

34. Paiaguás

117. Área de Expansão Urbana

Fonte: Organizado pelas Autoras 
A Tabela 4 apesenta o Índice de Área Verde Urbanizada - IAVP, o qual tem sua base de cálculo na disponibilidade de AVPU para cada habitante do bairro. Segundo Troppmair e Galina (2003), a ONU (Organização das Nações Unidas) recomenda que seja adotado "12 metros quadrados de área verde por habitante para que haja equilíbrio entre a quantidade de oxigênio e gás carbônico".

Tabela 4 - IAVPU da Zona Norte da Cidade de Cuiabá-MT

\begin{tabular}{l|l|c|c|c}
\hline Cd. & $\begin{array}{l}\text { BAIRRO DA ZONA } \\
\text { NORTE }\end{array}$ & POPULAÇÃO(i) & AVPU /M2 & IAVPU \\
\hline 25 & Jardim Florianópolis & 4.824 & $2.427,98$ & 0,50 \\
\hline 26 & Jardim Vitória & 8.966 & 0 & 0 \\
\hline 27 & Paraíso & 5.655 & 0 & 0 \\
\hline 28 & Nova Conquista & 855 & 0 & 0 \\
\hline 29 & Primeiro De Março & 7.457 & 0 & 0 \\
\hline 30 & Três Barras & 9.926 & $7.104,65$ & 0,71 \\
\hline 31 & Morada da Serra & 56.066 & $62.585,26$ & 1,11 \\
\hline 32 & Morada do Ouro & 5.824 & $3.641,00$ & 0,62 \\
\hline 33 & Centro Político & 5.434 & $829.484,00$ & 152,64 \\
& Administrativo & & & \\
\hline 34 & Paiaguás & 4.743 & $4.094,95$ & 0,86 \\
\hline 117 & Área de Expansão Urbana & 11.164 & 0 & 0 \\
\hline
\end{tabular}

1 - População segundo dados coletados pelo Censo IBGE, 2010

2 - AVPU/M2 - Área Verde Pública Urbanizada por metro quadrado

3 - IAVPU - Índice de Área Verde Pública Urbanizada

Fonte: Organizado pelas Autoras

Figura 3 - Mapa do IAVPU por loteamento na Zona Norte da Cidade de Cuiabá-MT

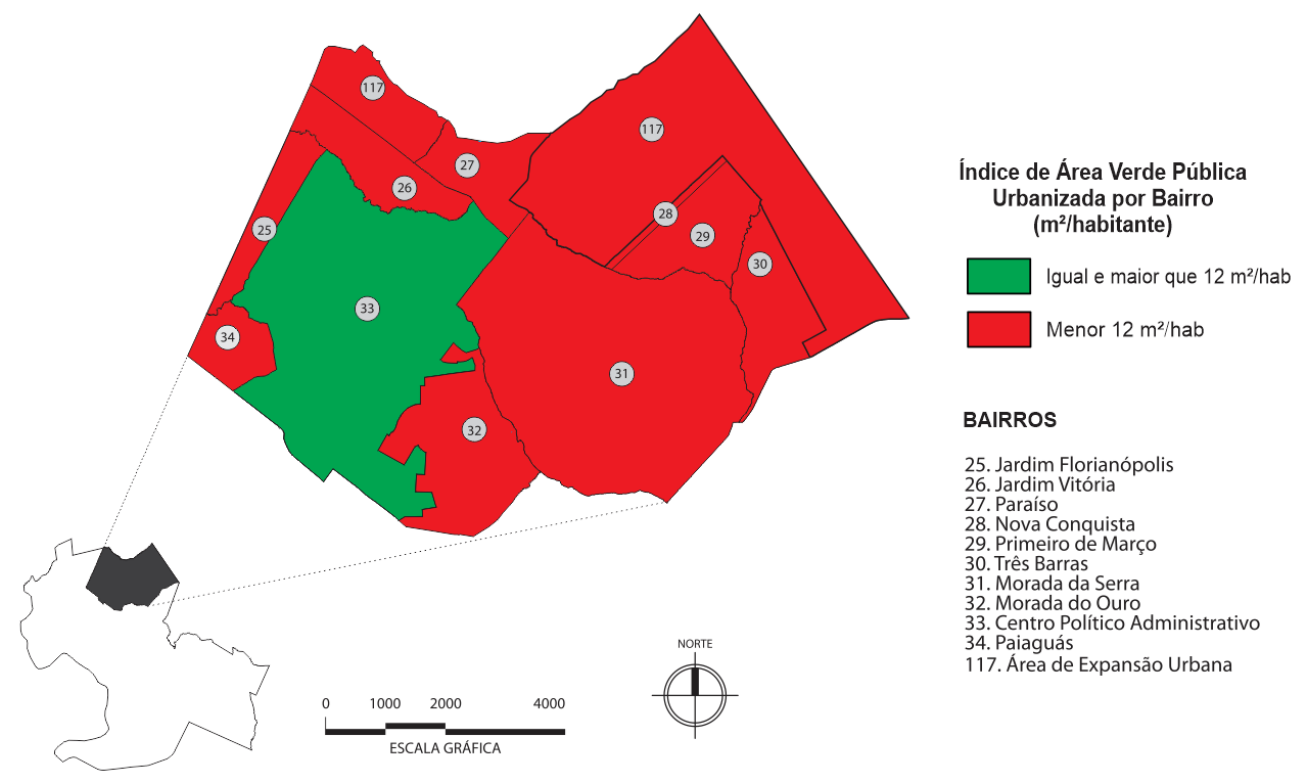

Fonte: Organizado pelas Autoras 
A espacialização do IAVPU da Zona Norte de Cuiabá na Figura 3, permite verificar que apesar da predominância da altas temperaturas na região, o que demandaria a oferta de mais áreas verdes, a maior parte da área estuda apresenta um índice abaixo do ideal recomendado pela ONU.

\section{CONCLUSÃO}

O conteúdo apresentado neste artigo evidência que a Zona Norte da cidade de Cuiabá apresenta uma carência, não só na quantidade de espaços públicos destinados ao lazer e recreação, bem como a qualidade desses espaços, o que denota a ausência de politicas públicas direcionadas pa população de menor poder aquisitivo.

Ao mensurar o IAVPU, verificou-se que necessidade de implantação de novos espaços, com observância a Lei de Parcelamento de Solo, de modo melhorar de uma qualidade ambiental da população.

\section{REFERÊNCIAS}

ANGELIS, Bruno Luiz de; CASTRO, Rosana Miranda de; ANGELIS NETO, G.

Metodologia para levantamento, cadastramento, diagnóstico e avaliação de praça no Brasil. Engenharia Civil. UM, n.20, p. 57-70, 2004. Disponível em:

http://www.civil.uminho.pt/cec/revista/Num20/Pag\%2057-70.pdf. Acesso em: 5 set. 2020.

ÁVILA, Adriano Dias et. al.. Análise de revestimentos de cobertura do solo em parque urbano na cidade de Cuiabá-MT-Brasil. ANAIS... XIII Encontro Nacional e IX Encontro Latino-americano de Conforto no Ambiente Construído, 2015. Disponível em< http://www.infohab.org.br/encac/files/2015/topico3artigo07.pdf > Acesso $10 \mathrm{abr}$. 2020.

BARBIRATO, Gianna Melo; SOUZA, Léa Cristina Lucas de; TORRES, Simone Carnaúba. Clima e Cidade: a abordagem climática como subsídio para estudos urbanos. Maceió: EDUFAL, 2007, 164 p.

BENINI, Sandra Medina. Áreas Verdes Públicas: A construção do conceito e a análise geográfica desses espaços no ambiente urbano. Presidente Prudente: 2009. Dissertação (mestrado) - Universidade Estadual Paulista, Faculdade de Ciências e Tecnologia, 2009.

BENINI, Sandra Medina. Infraestrutura verde como prática sustentável para subsidiar a elaboração de planos de drenagem urbana: estudo de caso da cidade de Tupã/SP. Tese (doutorado) - Universidade Estadual Paulista, Faculdade de Ciências e Tecnologia. Presidente Prudente, 2015. 
BENINI, S. M.. Landscape planning of the city of Cuiabá - MT: Case study of urbanized green areas in the Westside. Revista Nacional De Gerenciamento De Cidades, 8(67), 2020. https://doi.org/10.17271/2318847286720202735

CAVALHEIRO, Felisberto et al. Proposição de terminologia para o verde urbano. Boletim Informativo Sociedade Brasileira de Arborização Urbana, Rio de Janeiro: SBAU, ano VII, n.3, p.7, jul./ago./set. 1999.

DANNI-OLIVEIRA, Inês Moresco. A cidade de Curitiba e a Poluição do ar: Implicações de seus atributos urbanos e geoecológicos na dispersão de poluentes em período de inverno. In: MONTEIRO, Carlos Augusto de Figueiredo; MENDOÇA, Francisco (Org.). Clima Urbano. São Paulo: Contexto, 2003, p.155-172.

GOMES, Marcos Antônio Silvestre. As praças de Ribeirão Preto-SP: uma contribuição geográfica ao planejamento e à gestão dos espaços públicos. 204 f. 2005. Dissertação (Mestrado) Universidade Federal de Uberlândia, Programa de PósGraduação em Geografia. Uberlândia, 2005.

LIMA, Ana Maria Liner Pereira et al. Problemas de utilização na conceituação de termos como espaços livres, áreas verdes e correlatos. In. $2^{\circ}$ Congresso Brasileiro Sobre Arborização Urbana, 1994, ANAIS... São Luís. p. 539-550.

LOBODA, Carlos Roberto; ANGELIS, Bruno Luiz Domingos de. Áreas Públicas Urbanas: conceito, uso e funções. Ambiência. Guarapuava, PR, v.1 n.1, p. 125-139, jan./jun. 2005.

LOUREIRO, Maria Amélia Salgado. A cidade e as áreas verdes. São Paulo: Secretaria de Serviços e Obras do Município, 1979, 185 p.

LÜDKE, Menga; ANDRÉ, Marli E. D. A. Pesquisa em educação: abordagem qualitativa. São Paulo: EPU, 1986, 99 p.

MACEDO, Silvio Soares; SAKATA, Francine Gramacho. Parques Urbanos no Brasil. São Paulo: Edusp, Impressa Oficial do Estado, 2002. 208 p.

MILANO, M. S.. Planejamento da arborização urbana: relação entre áreas verdes e ruas arborizadas. In: Encontro Brasileiro sobre Arborização Urbana, 4, 1990. Curitiba.

Anais... Curitiba: Sociedade Brasileira de Arborização Urbana, 1990.

MONTEIRO, Carlos Augusto de Figueiredo. Teoria do clima urbano: Um projeto e seus caminhos. In: MONTEIRO, Carlos Augusto de Figueiredo; MENDOÇA, Francisco (Org.). Clima Urbano. São Paulo: Contexto, 2003, p. 9 -67.

NIEMEYER, Carlos Augusto da Costa. Paisagismo no planejamento arquitetônico. Uberlândia: EDUFU, 2005, 127 p.

NOGUEIRA, A.; WANTUELFER, G.. Florestas Urbanas: planejamento para melhoria da qualidade de vida. Viçosa: Aprenda Fácil, 2002.

NUCCI, João Carlos. Qualidade ambiental e adensamento urbano: um estudo de ecologia e planejamento da paisagem aplicado ao distrito de Santa Cecília (MSP). $2^{\mathrm{a}}$ ed. Curitiba: O Autor, 2008. 150 p. 
PISSOL, Kátia Maria Santos de Andrade. A Dinâmica Urbana: Uma Leitura da Cidade e da Qualidade de Vida no Urbano. Caminhos de Geografia, Uberlândia - MG, v. 7, n. 17 , p. $1-7$, fev. 2006,

ROBBA, F; MACEDO, S. S.. Praças brasileiras: public squares in Brazil. São Paulo: Edusp: Imprensa oficial do Estado. 2002, 312p.

SPIRN, Anne Whiston. O Jardim de Granito: A natureza no desenho da cidade. Tradução Paulo Renato Mesquita Pellegrino. São Paulo: Edusp, 1995. 345 p.

SANTIAGO, Zilsa Maria Pinto; SANTIAGO, Cibele Queiroz de; SOARES, Thaís Silveira. Acessibilidade no espaço público: o caso das praças de Fortaleza. Ergodesign e HCI, Rio de Janeiro-RJ, v. 4, n. 2, p. 32-29, 2016.

TROPPMAIR, Helmut; GALINA, Márcia Helena. Áreas verdes. Território \& Cidadania. Rio Claro, SP, ano III, nº 2, jun-dez, 2003. 